\title{
Preparation and physical properties of phthalonitrile composite foam filled with hollow glass microspheres
}

\author{
Ping Yuan ${ }^{1}$, Yong Qiu ${ }^{2, *}$, Yuhong Huang ${ }^{1, *}$, Juying Wu${ }^{1}$, Jinghui Fan ${ }^{1}$, Kai Zhang ${ }^{1}$, Ren He $^{1}$, Tao Xing ${ }^{1}$ \\ ${ }^{1}$ China Academy of Engineering Physics, Institute of Systems Engineering, 621900 Mianyang, China \\ ${ }^{2}$ China Academy of Engineering Physics, 621900 Mianyang, China
}

\begin{abstract}
In this work, a series of phthalonitrile/hollow glass microsphere (HGM) composite foams for applications in the high temperature and flame retardant fields were prepared and characterized. First, Blends of bisphthalonitrile $(\mathbf{C N})$ and alicyclic imide compounds synthesized from tetrahydrophthalic anhydride (CC) were prepared and sieved (>100 mesh), based on the Thermal Synergistic Polymerization (TSP) effect between phthalonitrile and the alicyclic imide compounds, namely, the $-\mathrm{C} \equiv \mathrm{N}$ of the phthalonitrile compound could be completely and rapidly consumed. Then thermogravimetric analysis and rheological behaviors of different molar ratios of $\mathbf{C C} / \mathbf{C N}$ blend at different temperatures were investigated. HGM were modified using a silane coupling agent (KH550) to improve the interface interaction between HGM and the resin, thereby improving the properties of composite foam. Finally, a series of composite foams were fabricated and characterized. The performance of the foam prepared by BMC method is much better than that of the foam prepared by "RTM" method. The foam (BMC) shows a density of $0.47 \mathrm{~g} / \mathrm{cm}^{3}$ with no obvious volume change and little voids, also exhibits good thermal stability up to $400{ }^{\circ} \mathrm{C}$ and low thermal conductivity, and provides UL94 V0-rated flame retardancy with total HR of $21.5 \mathrm{KJ} / \mathrm{g}$.
\end{abstract}

\section{Introduction}

The phthalonitrile (PN) resins constitute a class of hightemperature polymers that exhibit a number of outstanding properties such as excellent thermal and thermos-oxidative stability, excellent high-temperature mechanical properties, chemical resistance, low water absorption and superior flame-retardant properties. [1-5] Especially, phthalonitrile resin have been used as the only organic polymer material meeting the fireproof performance standard of U.S. Navy submarine materials (MIL-STD-2031). In addition, phthalonitrile monomers and oligomers possess a low complex melt viscosity (0.01-1 Pa.s) which enables facile processing by cost effective processing techniques and no volatile byproducts evolved during the processing stage. [6] The combination of good processability and excellent hightemperature properties makes the phthalonitriles attractive for many military and civilian advanced technological applications. However, the polymerization of the neat resin is extremely sluggish which limits their scope of application. [2] To address this problem, considerable research efforts have been expended on the development for effective additions to accelerate the curing rate. Recently, new studies have reported that certain alicyclic imide curing agents can achieve highefficiency curing of phthalonitrile monomer through a high temperature free radical process. [7,8] And the unique phenomenon is namely Thermal Synergistic Polymerization (TSP), which is, the respective homopolymerization of the components in the blends is extremely sluggish even at high temperatures $\left(>300{ }^{\circ} \mathrm{C}\right)$, but the polymerization rates of the blends can be accelerated significantly at elevated temperatures. The studies open an exciting opportunity for fabricating new high performance thermosetting polymers and composites.

With rapid development of aerospace, naval vessels, transportation machinery, electronic information, and defense and military high-end equipment industries in the direction of miniaturization, light weight and high reliability, there is an urgent need for light weight, high temperature resistant composites.

Hollow glass microspheres (HGMs) are inorganic material, which consist of outer stiff glass and inner inert gas, resulting in some unique properties, such as light weight, dispersibility, fluidity, stability and low thermal conductivity. [9-12] Based on these properties, HGMs have been extensively used as reinforcing or functional fillers in the past decades in the construction industry, chemical industry, aerospace industry, and so forth. This makes it more suitable for the above applications compared to open cell structured foams, and other lowdensity materials. [13-18] It is therefore important to develop novel composite materials meeting special functional applications by taking advantage of the superiority of both phthalonitrile resin and HGMs.

At present, phthalonitrile resins are mainly used as a matrix to prepare fiber-reinforced composite materials, sheet molding compounds, etc., but there are very few reports on its application in the preparation of foam

Corresponding author: hyh99168@163.com 
materials. In this work, hollow glass microsphere-filled phthalonitrile composite foams were fabricated by green solvent-free method. The thermal-physical properties of thermal conductivity and flame retardancy were also investigated. At the same time, the microstructural features of the composites were analysed by scanning electron microscope (SEM).

\section{Experimental}

\subsection{Raw materials}

The HGMs are white-colored tiny hollow spheres. Its manufacture involves complex processes, thus it is difficult to fabricate uniform HGMs with identical size and wall thickness, as indicated in the scanning electron microscope (SEM) photograph in Figure 1(a). In this work, the HGMs (trade mark: GS20), supplied by Sinosteel Maanshan General Institute of Mining Research Co. Ltd. (Anhui, China), are used as lightweight fillers. Table 1 lists the properties of the microspheres. The coupling agent was 3aminpropyltriethoxysilane (trade name: KH550), purchased from Zhonglan Chenguang Chemical Research Institute of Co., Ltd (Sichuan, China). The tetrahydrophthalic anhydride end-capped imide compound (CC) (Scheme 1) was synthesized from cis-1, 2, 3, 6-tetrahydrophthalic anhydride and 4,4'oxydianiline in DMAc/toluene solvent. The bisphthalonitrile compound $(\mathbf{C N})$ was synthesized from 4-nitrophthalotrile and resorcinol in $\mathrm{K}_{2} \mathrm{CO}_{3} / \mathrm{DMSO}$ solvent. Both synthesis of $\mathbf{C C}$ and $\mathbf{C N}$ were performed according to a literature procedure. [8] Ethanol was acquired from Chengdu Kelong Chemical Co., Ltd. (Sichuan, China). All other solvents (Sinopharm Chemical Regent Co., Ltd., AR) were used as received without further purification.

\subsection{Sample preparation}

\subsubsection{HGM modification}

The silane coupling agent (KH550) was employed to modify the interfacial interaction of HGMs. Firstly, HGMs were dispensed in ethanol and ultrasonicated for $1 \mathrm{~h}$ at room temperature. This process is conducive to the formation of hydroxyl groups on the surface of HGMs. Then, 1.0 wt $\%$ of KH550 solution was added dropwise into the above suspension, followed by low speedstirring for $2 \mathrm{~h}$ at $80{ }^{\circ} \mathrm{C}$ to complete the silylation reaction on the HGMs surface. Finally, the surfacemodified HGMs were collected and dried at $120^{\circ} \mathrm{C}$ and further sieved ( $80 \mathrm{mesh}$ ) to obtain fine microspheres.

\subsubsection{Preparation of blends and fabrication of CC/CN/HGM composite foam}

Blends $(\mathbf{C C} / \mathbf{C N})$ by different molar ratios $(2: 8,3: 7,5: 5)$ were prepared (1) with each compound by crushing and sieving by 100 mesh, and (2) by mixing well to insure homogeneity. Then, blends of $\mathbf{C C} / \mathbf{C N} / \mathrm{HGM}$ were prepared by mixing $\mathbf{C C} / \mathbf{C N}$ with about $30 / 70$ (wt/wt) KH550-modified HGM.

The mixture was poured into a cylindrical mold and left to cure in inert atmosphere in vacuum according to two programmed schedules: (1) $\mathbf{C C} / \mathbf{C N}$ melting, immersing HGM and curing ("RTM" method): $200{ }^{\circ} \mathrm{C}$ for $6 \mathrm{~h}, 230^{\circ} \mathrm{C}$ for $3 \mathrm{~h}, 270{ }^{\circ} \mathrm{C}$ for $6 \mathrm{~h}, 310^{\circ} \mathrm{C}$ for $6 \mathrm{~h}$, $330{ }^{\circ} \mathrm{C}$ for $3 \mathrm{~h}$ and $350{ }^{\circ} \mathrm{C}$ for $3 \mathrm{~h}$, and (2) Blending CC/CN and HGM, melting and curing (BMC method): $200{ }^{\circ} \mathrm{C}$ for $2 \mathrm{~h}, 230{ }^{\circ} \mathrm{C}$ for $2 \mathrm{~h}, 270^{\circ} \mathrm{C}$ for $2 \mathrm{~h}, 310^{\circ} \mathrm{C}$ for $2 \mathrm{~h}$ and $350{ }^{\circ} \mathrm{C}$ for $2 \mathrm{~h}$. The resulting CC/CN/HGM composite foams were cut into different shapes for specific characterization.

\subsection{Characterization}

Generally, the physical properties of a composite foam are strongly related to its microstructure, which may involve the volume content, spatial dispersion, interfacial bonding and shape of fillers. The microstructural features of the composite foams were analysed by Phenom GZ proX scanning electron microscope (SEM). The rheological behavior of $\mathbf{C C}, \mathbf{C N}$ and their blends was studied by dynamic oscillation employing a TA Instruments AR-2000ex rheometer. FTIR spectra were carried out using PerkinElmer Frontier FTIR spectrometer. $\mathrm{Tg}$ and thermogravimetric analysis were measured with PerkinElmer thermal analyzers (Differential Scanning Calorimeter DSC8000, Simultaneous Thermal Analyzer STA8000) in flowing nitrogen atmosphere. The temperature range used was from 30 to $700{ }^{\circ} \mathrm{C}\left(400{ }^{\circ} \mathrm{C}\right)$ and the heating rate was $10{ }^{\circ} \mathrm{C} / \mathrm{min}$. The thermal conductivity of the composite foams was measured by the Mathis TCi thermal conductivity analyzer (Setaram Corporation) at room temperature. The samples were cylindrically shaped, $20.0 \mathrm{~mm}$ in diameter and $5 \mathrm{~mm}$ in thickness. Limited oxygen index(LOI) were tested by LFY-605 limiting oxygen index analyzer (Shandong texile science research institute) following ASTM D2863-2009. Combustion properties were tested by HK-HVR horizontal and vertical combustion tester (Zhuhai huake testing equipment Co., Ltd) following GB/T 2408-2008, with approximate dimensions $127 \mathrm{~mm} \times 12.7 \mathrm{~mm} \times 3.2 \mathrm{~mm}$. Micro-scale combustion calorimeter (MCC), FAA type, manufactured by Fire Testing Technology Co., Ltd., UK, was used to determine the heat release rate (HRR), the peak value of heat release rate (PHRR), capacity and the total heat release (THR) of the materials with a heating rate of $1^{\circ} \mathrm{C} / \mathrm{s}$ from $100^{\circ} \mathrm{C}$ to $750^{\circ} \mathrm{C}$. 
Table 1. Physical properties of HGM (GS20).

\begin{tabular}{|c|c|c|c|c|c|c|c|c|}
\hline \multirow{2}{*}{$\begin{array}{l}\text { Target crush strength } \\
\text { (90\% survival, MPa) }\end{array}$} & \multirow{2}{*}{$\begin{array}{l}\text { True density } \\
\left(\mathrm{g} / \mathrm{cm}^{3}\right)\end{array}$} & \multirow{2}{*}{$\begin{array}{l}\text { Tap density } \\
\left(\mathrm{g} / \mathrm{cm}^{3}\right)\end{array}$} & \multirow{2}{*}{$\begin{array}{l}\text { Moisture } \\
(\%)\end{array}$} & \multirow{2}{*}{$\begin{array}{l}\text { Floating rate } \\
(\%)\end{array}$} & \multicolumn{3}{|c|}{$\begin{array}{l}\text { Particle size distribution }(\mu \mathrm{m}, \text { by } \\
\text { volume) }\end{array}$} & \multirow[t]{2}{*}{ pH } \\
\hline & & & & & $10^{\text {th }} \%$ & $50^{\text {th }} \%$ & $90^{\text {th }} \%$ & \\
\hline 3 & 0.19 & 0.11 & 0.45 & 97 & 35 & 65 & 109 & 7.7 \\
\hline
\end{tabular}

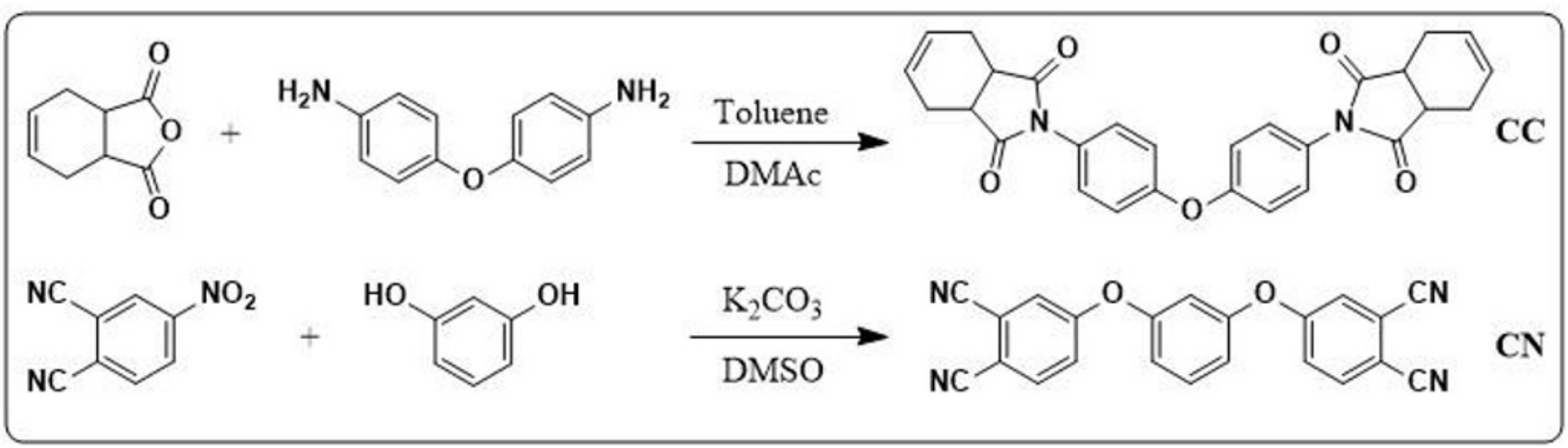

Scheme 1. Synthesis of $\mathbf{C C}$ and $\mathbf{C N}$.

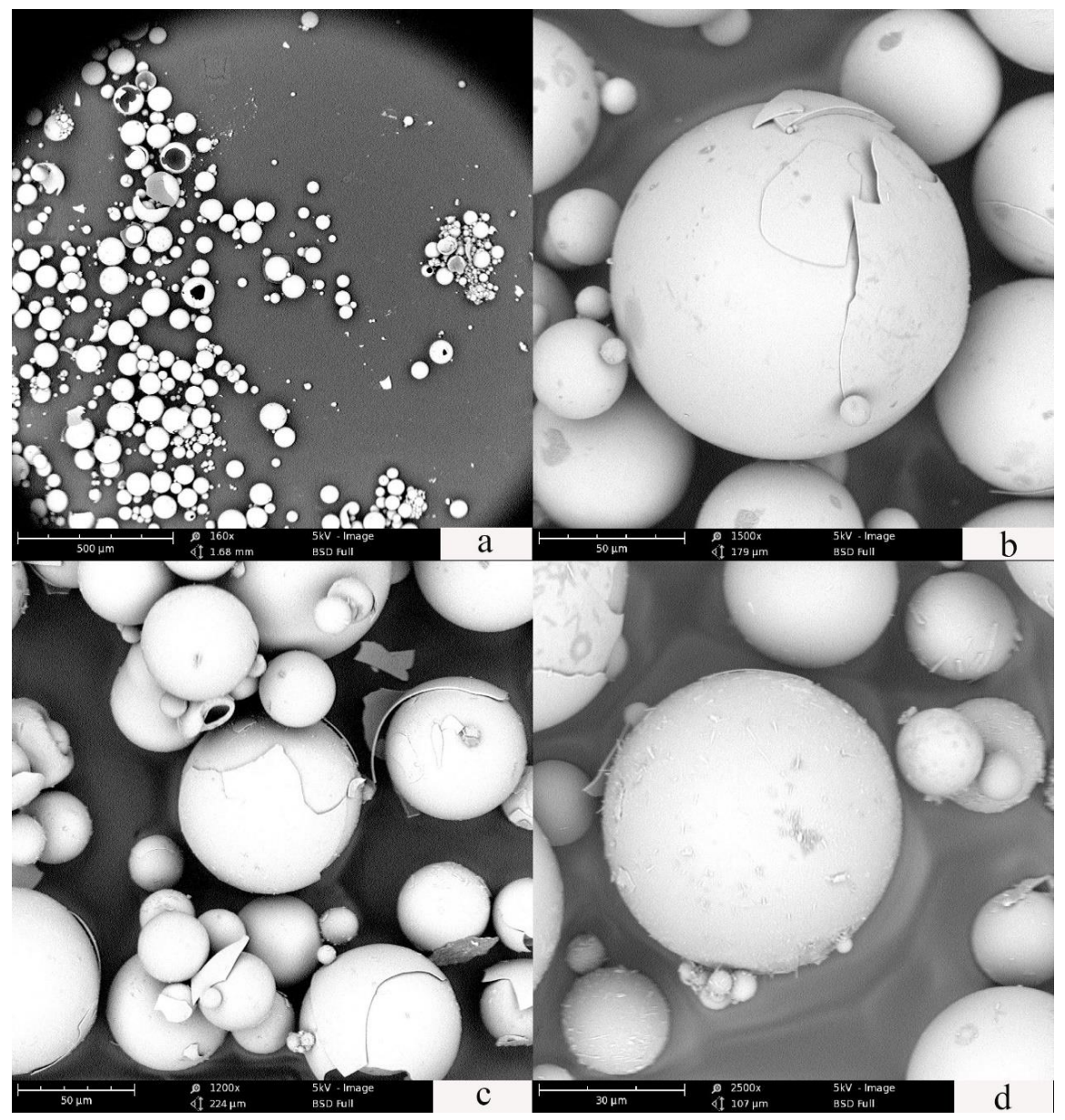

Figure 1. HGM before and after modification by KH550.

a, b: HGM before modification by KH550; c, d: HGM after modification by KH550 

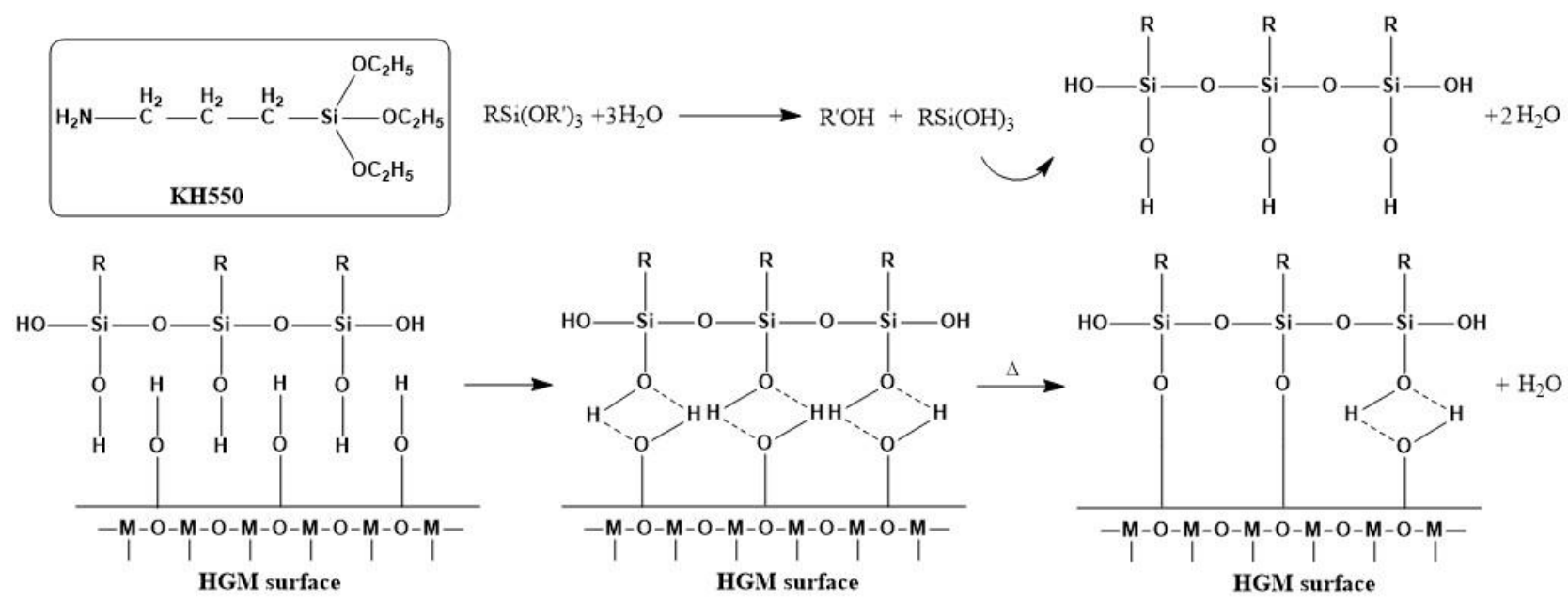

Scheme 2. Modification mechanism of KH550 on HGM.

Table 2. TGA and DSC data of $\mathbf{C C}, \mathbf{C N}$ and their blends.

\begin{tabular}{ccccccc}
\hline \multirow{2}{*}{ sample } & \multicolumn{2}{c}{ TGA } & \multicolumn{3}{c}{ DSC } \\
\cline { 2 - 6 } & $\mathbf{T}_{\mathbf{d}}, \mathbf{5 \%}$ & Char Yield at $\mathbf{7 0 0}{ }^{\circ} \mathrm{C}$ & Tendo $^{\text {onset }}$ & Tendo $^{\text {peak }}$ & Texo $^{\text {onset }}$ & Texo $^{\text {peak }}$ \\
\hline $\mathbf{C C}$ & $364^{\circ} \mathrm{C}$ & $13.0 \%$ & $229^{\circ} \mathrm{C}$ & $240^{\circ} \mathrm{C}$ & No significant exotherm \\
$\mathbf{C N}$ & $353^{\circ} \mathrm{C}$ & $9.7 \%$ & $169^{\circ} \mathrm{C}$ & $185^{\circ} \mathrm{C}$ & was observed. \\
$\mathbf{C C - C N - 2 8}$ & $344^{\circ} \mathrm{C}$ & $56.0 \%$ & $162^{\circ} \mathrm{C}$ & $177^{\circ} \mathrm{C}$ & $313^{\circ} \mathrm{C}$ & $331^{\circ} \mathrm{C}$ \\
$\mathbf{C C}-\mathbf{C N - 3 7}$ & $359^{\circ} \mathrm{C}$ & $67.0 \%$ & $161{ }^{\circ} \mathrm{C}$ & $176^{\circ} \mathrm{C}$ & $302^{\circ} \mathrm{C}$ & $321^{\circ} \mathrm{C}$ \\
$\mathbf{C C}-\mathbf{C N - 5 5}$ & $344^{\circ} \mathrm{C}$ & $48.2 \%$ & $167^{\circ} \mathrm{C}$ & $176^{\circ} \mathrm{C}$ & $295^{\circ} \mathrm{C}$ & $321^{\circ} \mathrm{C}$ \\
\hline
\end{tabular}

Table 3. Gel time of $\mathbf{C C} / \mathbf{C N}$ blend at different temperatures.

\begin{tabular}{cccc}
\hline Gel time & $\mathbf{2 3 0}^{\circ} \mathbf{C}$ & $\mathbf{2 5 0}^{\circ} \mathbf{C}$ & $\mathbf{2 7 0}^{\circ} \mathbf{C}$ \\
\hline CC-CN-28 & $106.2 \mathrm{~min}$ & $35.2 \mathrm{~min}$ & $12.8 \mathrm{~min}$ \\
$\mathbf{C C}-\mathbf{C N}-\mathbf{3 7}$ & $59.8 \mathrm{~min}$ & $19.3 \mathrm{~min}$ & $6.7 \mathrm{~min}$ \\
$\mathbf{C C}-\mathbf{C N}-55$ & $53.3 \mathrm{~min}$ & $22.2 \mathrm{~min}$ & $10.8 \mathrm{~min}$ \\
\hline
\end{tabular}

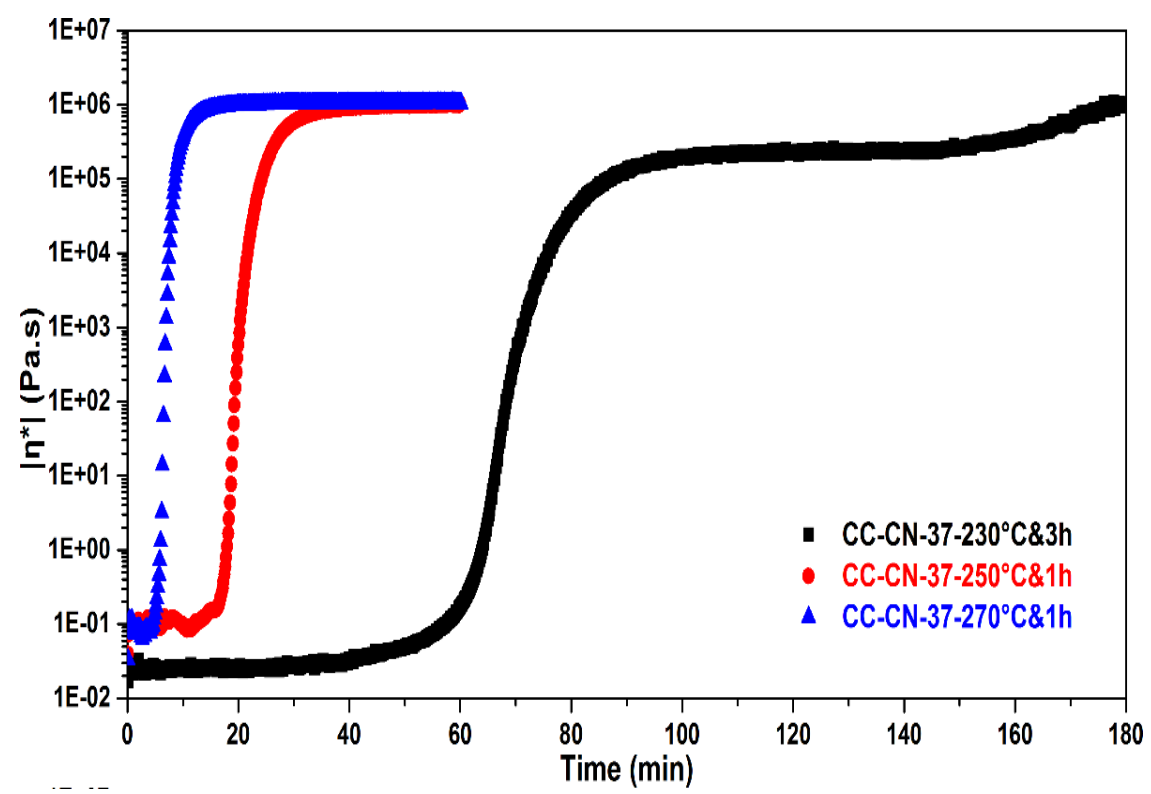

Figure 2. Complex viscosity $\left(\left|\eta^{*}\right|\right)$ as a function of time for compounds $\mathbf{C C} / \mathbf{C N}$ blends with molar ratio $3: 7$ at $230^{\circ} \mathrm{C}, 250{ }^{\circ} \mathrm{C}$ and $270{ }^{\circ} \mathrm{C}$ 


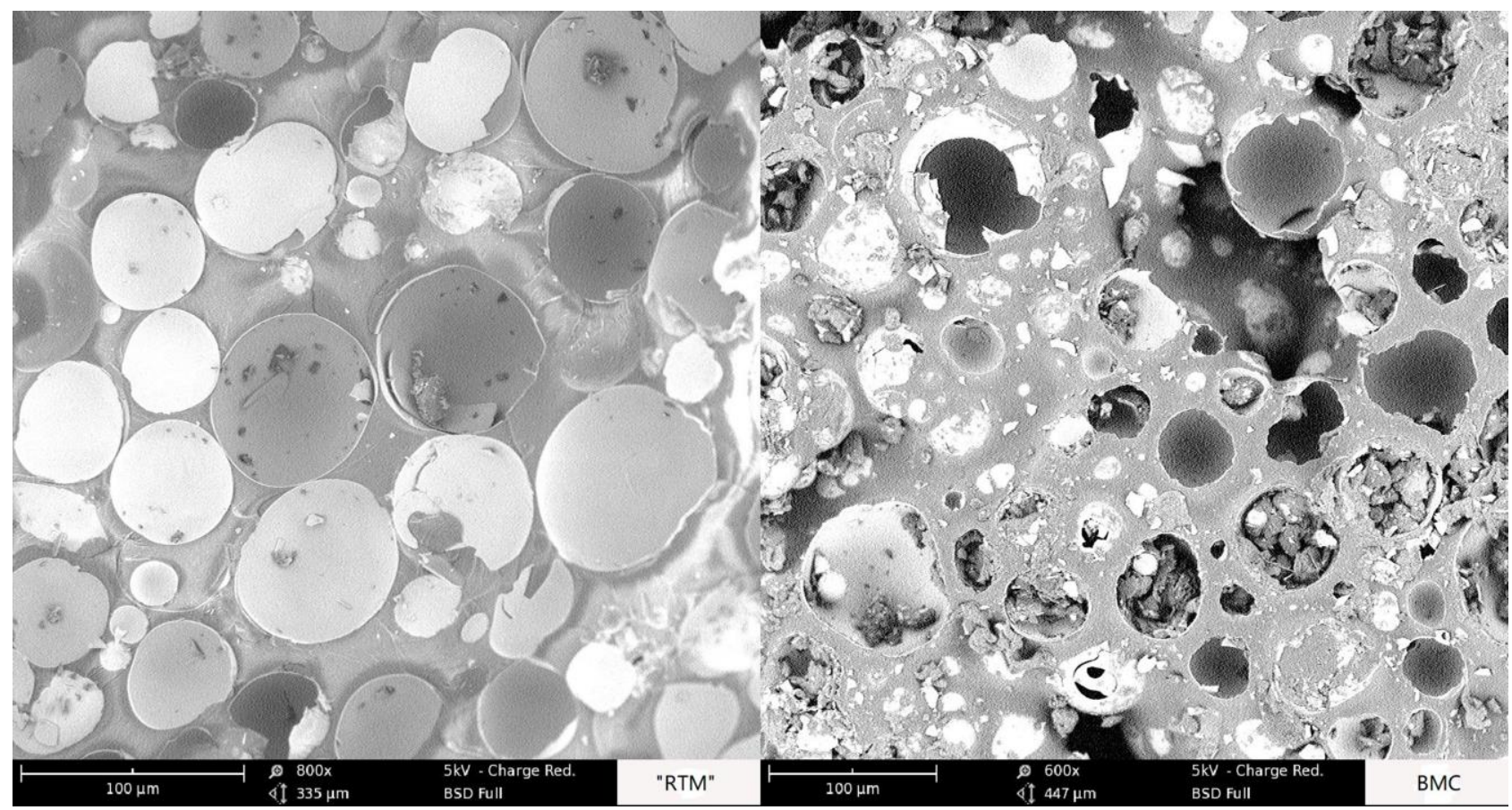

Figure 3. SEM micrographs of $\mathbf{C C / C N / H G M ~ c o m p o s i t e ~ f o a m s ~ b y ~ " R T M " ~ a n d ~ B M C ~ m e t h o d ~}$

Table 4. Thermal properties of $\mathbf{C C}-\mathbf{C N}-37 / H G M$ composite foam.

\begin{tabular}{ccc}
\hline Thermal properties $\left(\mathrm{N}_{2}\right)$ & Foam by "RTM" & Foam by BMC \\
\hline $\mathrm{T}_{5 \%}$ & $388^{\circ} \mathrm{C}$ & $499^{\circ} \mathrm{C}$ \\
$\mathrm{T}_{10 \%}$ & $415^{\circ} \mathrm{C}$ & $552^{\circ} \mathrm{C}$ \\
$\mathrm{Tg}$ & $218^{\circ} \mathrm{C}$ & Unobserved up to $400^{\circ} \mathrm{C}$ \\
Char yield at $700^{\circ} \mathrm{C}$ & $60.5 \%$ & $78.5 \%$ \\
\hline
\end{tabular}
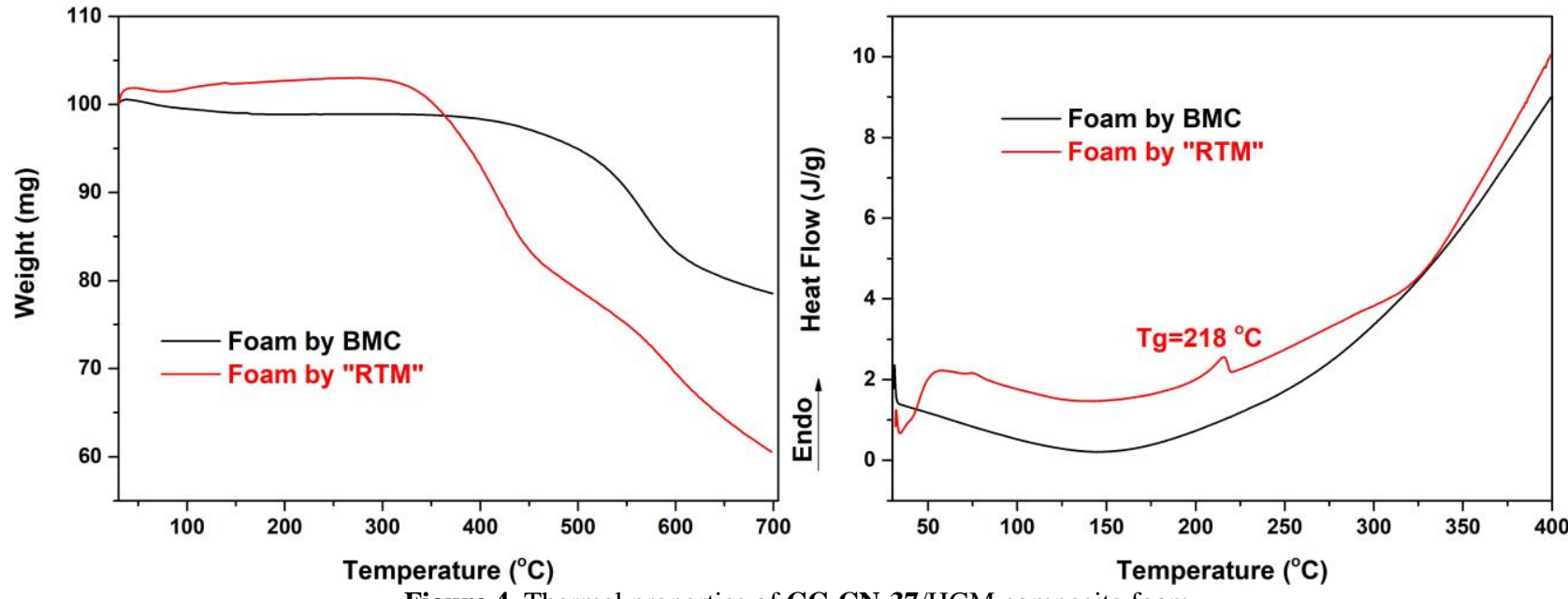

Figure 4. Thermal properties of CC-CN-37/HGM composite foam 

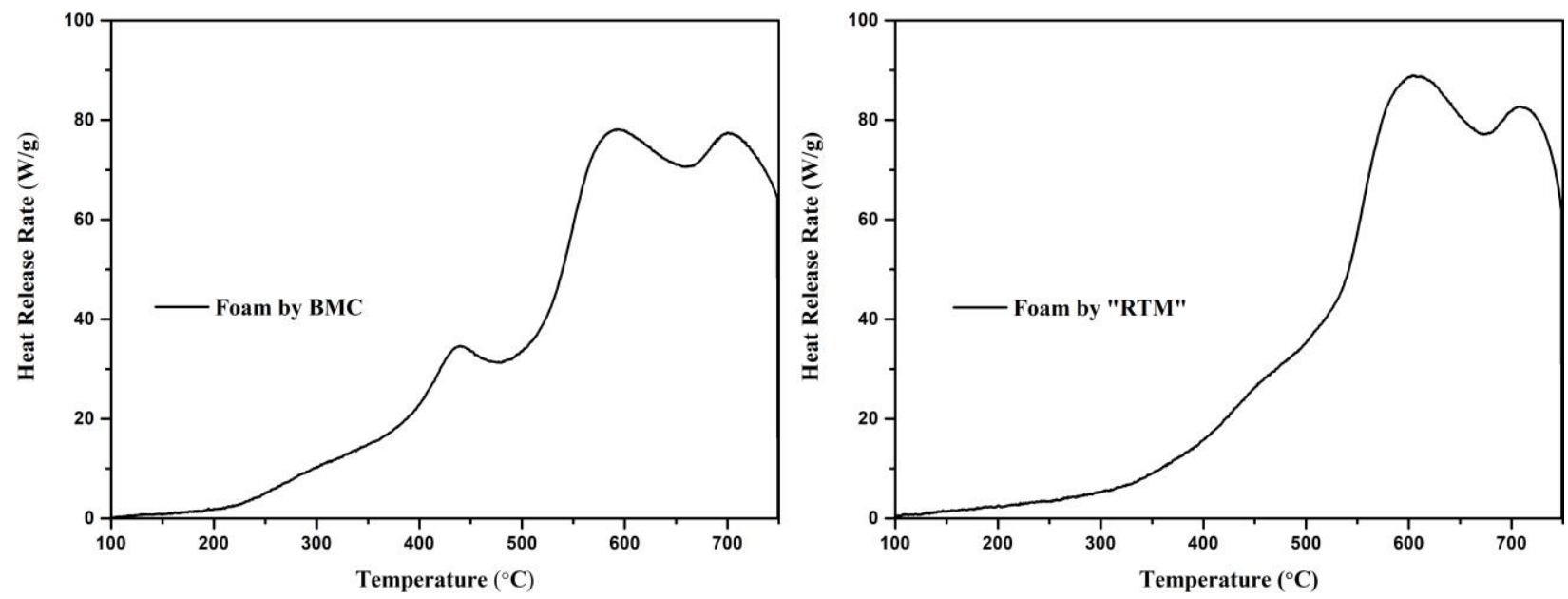

Figure 5. The HRR vs. temperature curves of CC-CN-37/HGM composite foam

\section{Results and discussion}

\subsection{Composite foam preparation}

The morphologies of HGM before and after surface modification by KH550 are shown in Figure 1 . Compared with pristine HGM, the KH550 modified HGM show more rough surface morphology due to the formation of network structures on the surface of HGM by condensation reaction of KH550 and HGM (Scheme 2).

Thermal stability and rheological behaviour of $\mathbf{C C}$, $\mathbf{C N}$ and their blends (molar ratio 2:8, 3:7 and 5:5) are measured by TGA, DSC and rheometer. The data are listed in Table 2, Table 3 and Figure 2, which reveals that the molar ratio of 3:7 for $\mathbf{C C} / \mathbf{C N}$ shows much better thermal stability with temperature $359{ }^{\circ} \mathrm{C}$ at $5 \%$ weight loss and could be cured at lower temperature for less time. Therefore, CC-CN-37 was preferred to prepare composite foam.

Microstructures of the fractured cross section of the foam prepared by BMC and "RTM" methods are shown in Figure 3. It is clearly seen that the HGMs disperse randomly in the composite material, as we expect. Also, there are less resin content for BMC foam, resulting lower density at $0.47 \mathrm{~g} / \mathrm{cm}^{3}$, compared with "RTM" foam for density at $0.63 \mathrm{~g} / \mathrm{cm}^{3}$. The FTIR spectra reveals that the foams have been completely cured with hardly $\mathrm{C} \equiv \mathrm{N}$ groups left.

\subsection{Thermal properties}

Table 4 and Figure 4 exhibit the thermal properties of the composite foams prepared by BMC and "RTM" methods. Also, the foam prepared by BMC method showed better thermal properties, giving $78.5 \%$ char yield at $700{ }^{\circ} \mathrm{C}$ and no obvious $\mathrm{Tg}$ are observed up to $400{ }^{\circ} \mathrm{C}$. The significant difference trend of thermal stability from "RTM" to BMC method, indicating that the stabilities of the composite foams were depended on the cure cycle and cure temperatures, which further illustrates that preparation process has a great influence on properties of composite materials.

\subsection{Thermal conductivity properties}

Thermal conductivity of the composite foam plays a vital role in determining the performance of thermal insulation. Thermal probe technique using transient plain source is widely used to determine the effective thermal conductivity of two phase materials. In thermal conductivity measurement, the central region of each sample is selected as the testing position and each sample plate is measured ten times. The averaged data are regarded as the foam thermal conductivity. Both kinds of the foam exhibit good thermal insulation properties, with foam by "RTM" method from 0.088 to $0.124 \mathrm{~W} /(\mathrm{m} \cdot \mathrm{K})$, and foam by BMC method from 0.060 to $0.094 \mathrm{~W} /(\mathrm{m} \cdot \mathrm{K})$. This can be attributed to the inert gas core enclosed in the HGM of the composite foams.

\subsection{Flame retardant properties}

The foam flame retardancy performance was measured by limiting oxygen index (LOI) which is the minimum concentration of oxygen to support the foam combustion; the measurement was undertaken through flowing a mixture of oxygen and nitrogen over a burning foam, and reducing the oxygen level until a minimum level is reached to sustain the combustion. The higher the limiting oxygen index, the more flame retardancy the sample is. The composite foam has a LOI of 37 , and it can be highly improved.

The UL-94 burning test was used to determine total flame time, flammability, dripping behavior and selfextinguishing characteristics of the composite foams. Dripping behavior onto a cotton patch was used to evaluate the $\mathrm{V}$-grade under test conditions. The 1 st and 2nd flame time for sample after flame time (10s) are 1s and 0 s, respectively. There was no dripping of sample observed during vertical burning ignited the cotton patch. As a result, the composite foam obtained a V-0 rating in UL-94 test, which indicates good flame retardant property.

The PHRR, THR and capacity of the composite foams prepared by BMC methods were $76.52 \mathrm{w} / \mathrm{g}, 21.5$ $\mathrm{KJ} / \mathrm{g}$ and $79 \mathrm{~J} /(\mathrm{g} \cdot \mathrm{K})$, respectively, and for foams prepared by BMC methods, $87.63 \mathrm{w} / \mathrm{g}, 21.6 \mathrm{KJ} / \mathrm{g}$ and 90 
$\mathrm{J} /(\mathrm{g} \cdot \mathrm{K})$, respectively. The HRR vs. temperature curves of the two samples are shown in Figure 5. It can be seen that the HRR vs. temperature curves of them are almost identical.

\section{Conclusion}

We synthesized bisphthalonitrile and tetrahydrophthalic anhydride endcapped imide compounds, and prepared KH550 modified hollow glass microspheres. Phthalonitrile composite foams filled with the modified hollow glass microspheres were successfully fabricated afterwards by two processing method: (1) $\mathbf{C C} / \mathbf{C N}$ melting, immersing HGM and curing ("RTM" method) and (2) Blending $\mathbf{C C} / \mathbf{C N}$ and HGM, melting and curing (BMC method). Compared with the foams prepared by "RTM" method, totally, the foams prepared by BMC method were found to exhibit better thermal, thermal conductivity and flame retardant properties, with a density of $0.47 \mathrm{~g} / \mathrm{cm}^{3}$ with no obvious volume change and little voids, low thermal conductivity, and provides UL94 V0-rated flame retardancy with total HR of 21.5 $\mathrm{KJ} / \mathrm{g}$.

\section{Acknowledgement}

The authors gratefully acknowledge the National Natural Science Foundation of China (No. 51703213, No. 51803199) for financial support of this work.

\section{References}

1. A.P. Mouritz, E. Gellert, P. Burchill, K. Challis, Compos. Struct. 53 (2001)

2. S.B. Sastri, T.M. Keller, J. Polym. Sci. Part A Polym. Chem. 36 (1998)

3. D.D. Dominguez, H.N. Jones, T.M. Keller, Polym. Compos 25 (2004)

4. T.M. Keller, D.D. Dominguez, Polymer 46 (2005)

5. D. Augustine, D. Mathew, C.P. Reghunadhan Nair, Polym. Int. 62 (2013)

6. M. Laskoski, A. Neal, T.M. Keller, D.D. Dominguez, C.A. Klug, A.P. Saab, J. Polym.Sci. Part A Polym. Chem. 52 (2014)

7. S.C. Ji, P. Yuan, J.H. Hu, R. Sun, K. Zeng, G. Yang, Polymer 84 (2016)

8. P. Yuan, S. Ji, J. Hu, X. Hu, K. Zeng, G. Yang, Polymer. 102 (2016)

9. C. C. Hsu, K. C. Chang, T. C. Huang, L. C. Yeh, W. T. Yeh, W. F. Ji, J. M. Yeh, T. Y. Tsai. Micropor. Mesopor. Mat 198 (2014)

10. G. Gao, Y. Hu, H. Jia, P. Liu, P. Du, D. Xu, J Phys. Chem. Solids. 135 (2019)

11. H. Wang, F. Hou, C. Chang, Constr. Build. Mater. 265 (2020)

12. K. C. Yung, B.L. Zhu, T. M. Yue, C. S. Xie, Compos. Sci. Thechnol. 69 (2009)
13. H. Zhang, Y. Li, W. Tao, Appl. Therm. Eng. 114 (2017)

14. S. Araby, J. Li, G. Shi, Z. Ma, J. Ma, Compos. Part A, 101 (2017)

15. C. A. Ikutegbe, M. M. Farid, Renew. Sust. Energ. Rev. 131 (2020)

16. T. Suparanon, W. Phetwarotai, Int. J Biol. Macromol. 158 (2020)

17. S. Zhao, S. Hui, L. Liang, Q. Zhou, Q. Zhao, N. Li, H. Tan, T. Xu, Exp. Therm. Fluid Sci. 45 (2013)

18. H. Yang, Q. Fu, X. Cheng, R. K. K. Yuen, H. Zhang, Procedia Engineering 62 (2013) 